\title{
Zinc(II)-pyridine-2-carboxylate / 1-methyl-imidazole: a binary catalytic system for the synthesis of cyclic carbonates from carbon dioxide and epoxides
}

\author{
Thomas A. Zevaco*, Annette Janssen, and Eckhard Dinjus* \\ Forschungszentrum Karlsruhe GmbH, Institut für Technische Chemie-Chemisch-Physikalische \\ Verfahren, Postfach 3640, 76021 Karlsruhe, Germany \\ E-mail: thomas.zevaco@itc-cpv-fzk.de,eckhard.dinjus@itc-cpv-fzk.de
}

Dedicated to Professor E. Anders on the occasion of his $65^{\text {th }}$ birthday

\begin{abstract}
A new "halogen-free" binary catalytic system for the synthesis of cyclic carbonate from epoxides and carbon dioxide is described. The catalysis relies on a synergy between the main catalyst, zinc(II) pyridine-2-carboxylate, and a Lewis base, 1-methyl imidazole. In this preliminary study four epoxides have been tested and the operating capabilities of this system have been evaluated. Using propylene oxide as test substrate and performing the catalysis in a high-pressure NMR tube, allowed us to gather some spectroscopic information on this catalytic system and to propose a reaction mechanism.
\end{abstract}

Keywords: Epoxides, carbon dioxide, cyclic carbonate, zinc carboxylate, imidazole

\section{Introduction}

The abundance and benignity of carbon dioxide makes it an attractive alternative $\mathrm{C}_{1}$-synthon for many processes in the synthetic chemistry ${ }^{1}$. Moreover the possibility to bind carbon dioxide in useful molecules is one of the tools we definitely have to consider in a global " $\mathrm{CO}_{2}$ management". Up to now only four major industrial processes using carbon dioxide as a $\mathrm{C}_{1}$ building block are known: syntheses of salicylic acid, urea, methanol and cyclic carbonates ${ }^{1 \mathrm{a}}$. Other promising synthesis routes have been also documented in the literature but have yet to be up-scaled to reach the volumes found in these four exemplary $\mathrm{CO}_{2}$-based processes. Typical examples are the synthesis of aliphatic polycarbonates from $\mathrm{CO}_{2}$ and epoxides ${ }^{2}$ and the synthesis of potential building-blocks for specialty polymers such as, e.g. lactones ${ }^{3}$, pyrones ${ }^{4}$ or formoxysilane ${ }^{5}$ obtained from butadiene (respectively alkynes or silanes) and $\mathrm{CO}_{2}$. 
Considering the cyclic carbonates, many important technical applications have been reported in the last years. Ethylene- and propylene carbonate owing to their good biodegradability, high boiling points and low toxicities are valuable solvents ${ }^{6}$. These polar molecules find a variety of applications as diluents and components in paint-, coatings and specialty resin formulations ${ }^{7}$ as well as electrolytes (so-called SEI: solid electrolyte interphase) in the production of lithium ion batteries ${ }^{8}$. Cyclic carbonate find also an application in the polymer chemistry: directly via reaction with diols or carboxylic acids to produce polyesters ${ }^{9}$ or indirectly via reaction with ammonia to form more reactive carbamates which eventually lead to polyurethanes ${ }^{10}$.

On the whole, the most reported " $\mathrm{CO}_{2}$-based" synthetic route to cyclic carbonates involves the use of an epoxide as substrate and a halide-containing main catalyst which is used in combination with a co-catalyst, most of the time a halide-containing quaternary onium salt ${ }^{11}$. Some of the documented systems deal with the use of specifically tailored quaternary onium salt, namely with the use of ionic liquids ${ }^{11 f-g}$, whereas other research group's focus on the use of transition metal complexes either soluble in the epoxide phase or supported on polymers or silica surface ${ }^{12}$. A last way involving basic metal oxides and zeolites has been relatively rarely documented and attracts an ever growing interest ${ }^{13}$.

Considering the most reported "metal halide/ quaternary onium salt" way more in detail, it can be noticed that the majority of the systems involves zinc halides $(\mathrm{Cl}$ or $\mathrm{Br})$. Since the pioneering work of Kisch and coworkers on catalytic systems involving $\mathrm{ZnCl}_{2}$ and $(\mathrm{n}-\mathrm{Bu})_{4} \mathrm{NI}{ }^{11 \mathrm{a}}$, many research groups focused on the optimization of this system ${ }^{11 \mathrm{e}-\mathrm{h}}$. However bearing in mind the general corrosion problems encountered in the industry when using halide-containing catalysts and considering this carbonate chemistry under the aspect of a "Green Chemistry", it seems advisable to develop catalytic systems involving no halides at all. Several "halogen-free" zinc-based systems were already reported in the activation of $\mathrm{CO}_{2}$. Zinc(II)-tetraazacycloalkane complexes are well-known to activate and transfer carbon dioxide to acidic substrates to afford for instance alkyl-carbonato derivatives ${ }^{14}$. Benzoic acid-based zinc carboxylates are also able to activate $\mathrm{CO}_{2}$ and catalyze a copolymerization of propylene oxide with $\mathrm{CO}_{2}{ }^{15}$. In relation to this, polymeric zinc (II) dicarboxylates like, e.g. zinc glutarate, are effective catalysts for the copolymerization of $\mathrm{CO}_{2}$ and epoxides ${ }^{16}$, although the exact nature of the active site of the catalysis remains speculative. On the search for a new alternative, we decided to focus on binary catalytic systems involving zinc (II) carboxylates with a definite, constrained geometry like 2pyridine-carboxylic acid (picolinic acid) and a Lewis base as a co-catalyst. The co-catalyst, 1methyl-imidazole ( $\mathrm{N}$-methyl imidazole: $\mathrm{NMi}$ ), is also known to display alone a high reactivity in the curing of epoxy resins ${ }^{17}$. 1-methyl imidazole as a co-catalyst should play a dual role in the reaction: by coordinating at the zinc center it should help solubilizing the zinc carboxylate into the epoxide $/ \mathrm{CO}_{2}$ reaction mixture and, on the other hand, it might activate the epoxide due to its high nucleophilicity. 


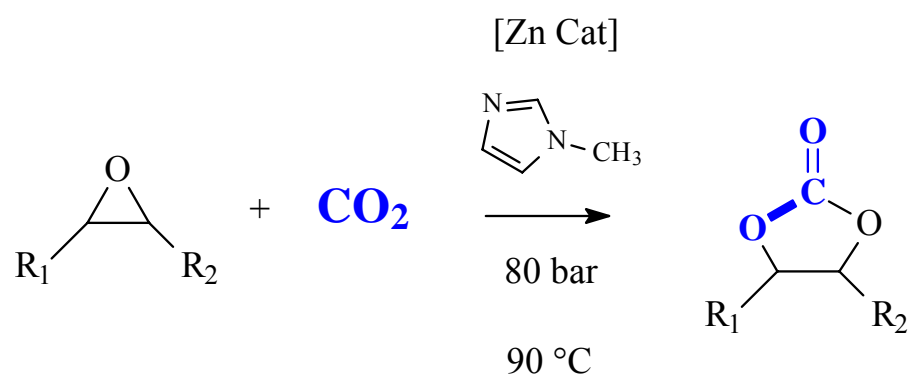

Scheme 1. Zinc picolinate/NMi-catalysed synthesis of cyclic carbonates from epoxides and $\mathrm{CO}_{2}$.

As a matter of fact, we found that this combination constitutes an effective system for the insertion of $\mathrm{CO}_{2}$ in terminal epoxides (scheme 1). We report here on the preliminary results of this novel catalytic system.

\section{Results and Discussion}

2<smiles>O=C(O)c1ccccn1</smiles>

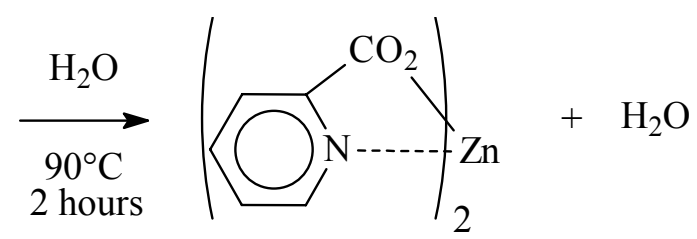

Scheme 2. Synthesis of zinc(II) pyridin-2-carboxylate from zinc oxide and pyridin-2-carboxylic acid.

Zinc 2-pyridine carboxylate was prepared via the "zinc oxide way" according to the literature ${ }^{16 a}$ (scheme 2). In a typical reaction zinc pyridine-2-carboxylate is added to the epoxide $(20 \mathrm{ml})$ to form a suspension. Two equivalents of 1-methyl-imidazole are then added to facilitate the solubilisation of the zinc carboxylate, the fastest solubilisation occurring when using styrene oxide as test substrate. The reaction mixture is then put under a $\mathrm{CO}_{2}$-atmosphere either under 1 bar, carbon dioxide being bubbled into the reaction mixture through a sintered glass or under ca. $60 \mathrm{bar} \mathrm{CO}_{2}$ in a stainless steel autoclave. The reaction mixture is then heated up to ca. $90^{\circ} \mathrm{C}$ to allow the reaction to take place. After the reaction time the reaction vessels were cooled down to RT and the carbon dioxide slowly vented, under stirring, in a fume hood. After opening the remaining solution was filtered/separated and analyzed with NMR and IR-FT. In some cases an oily residue could be noticed on the autoclave inner wall. This oil was collected and analyzed via IR- and NMR spectroscopy and revealed to be a mixture containing mainly zinc picolinate, 1methylimidazole, PO and traces of cyclic carbonate. Comparative tests without catalyst, respectively co-catalyst, were also run in order to evaluate the efficiency of the system. The preliminary results with four epoxides (propylene oxide -PO-, butene oxide -BO-, styrene oxide 
-SO- and cyclohexene oxide-CHO-) are summarized in Table I. The zinc-catalyzed conversion to cyclic carbonates was greatly facilitated under $\mathrm{CO}_{2}$-pressure and delivered, as anticipated, better yields of the carbonate in the presence of the 1-methyl-imidazole co-catalyst (entries 912). Performing the tests under 1 bar $\mathrm{CO}_{2}$ afforded the carbonate only in the case of styrene oxide with low yield (entry 18). The tests ran with 1-methyl-imidazol used alone, as main catalyst, under $\mathrm{CO}_{2}$-pressure, yielded in the case of styrene oxide significant amounts of the carbonate (entry 5). These results imply a kind of synergy between Lewis acid and Lewis base in the catalysis. In comparison, heating styrene oxide in the presence of 1-methyl-imidazol under argon lead to the expected formation of oligomers, products of the ring opening polymerization of the epoxide. The overall activity of the catalytic system can be ranked as follows: $\mathrm{PO}>\mathrm{SO}>$ BO $>$ CHO (entry 9-12). Cyclohexene oxide showed the lowest conversion under the chosen experimental conditions (entries $4,8,12,17$ ).

A substrate-to-catalyst molar ratio of 1 to 100 and a catalyst-to-cocatalyst molar ratio of 1 to 2 seemed to be an optimal reaction window for this system, a higher dilution $(1 / 2 / 1000)$ of the system afforded only traces of cyclic carbonate (entries 13-17). Interestingly running the test reaction with propylene oxide under high-dilution conditions $(1 / 2 / 1000$, entry 14$)$ showed no reactivity at all; however performing the same test with bigger amounts of 1-methyl-imidazole (1 / 20 / 1000, entry 15) afforded significant amounts of propylene carbonate with a notably higher carbonate yield than performed in the presence of 1-Me-imidazole alone (- / 1/ 100, entry 6). This again strongly suggests a cooperation between zinc carboxylate and 1-methyl imidazole in the catalysis. We ran a comparative test with a zinc complex containing 1-methyl-imidazole in the coordination sphere, $\mathrm{ZnCl}_{2}(\mathrm{NMi})_{2}$. As it might be expected from the literature ${ }^{11}$ the tests ran with $\left[\mathrm{ZnCl}_{2}(\mathrm{NMi})_{2}\right]$ as catalyst and $\mathrm{PO}$ or $\mathrm{SO}$ as epoxidic substrates delivered high amounts of the corresponding cyclic carbonates (entries 23-24) clearly showing that the zinc picolinate/NMi system is yet not competitive and needs a tuning of the different reaction parameters. 
Table 1. Effects of reaction parameters on the zinc picolinate/NMi -catalyzed formation of cyclic carbonate

\begin{tabular}{|c|c|c|c|c|}
\hline Entry & Temperature Pressure ${ }^{a}$ & Substrate & $\begin{array}{c}\text { Cat/Co-Cat./ } \\
\text { Substrate molar ratio }\end{array}$ & $\begin{array}{c}\text { Products } \\
\text { (yields \%) }^{\mathrm{b}}\end{array}$ \\
\hline 1 & $90 \pm 5^{\circ} \mathrm{C} 60 \pm 5$ bar & $\begin{array}{c}\mathrm{SO} \\
\text { (styrene oxide) }\end{array}$ & $1 /-/ 100$ & $<1$ \\
\hline 2 & $90 \pm 5^{\circ} \mathrm{C} 90 \pm 5$ bar & $\begin{array}{c}\text { PO } \\
\text { (propylene oxide) }\end{array}$ & $1 /-/ 100$ & 15 \\
\hline 3 & $90 \pm 5^{\circ} \mathrm{C} 90 \pm 5$ bar & $\begin{array}{c}\text { BO } \\
\text { (butene oxide) }\end{array}$ & $1 /-/ 100$ & $<1$ \\
\hline 4 & $90 \pm 5^{\circ} \mathrm{C} 80 \pm 5$ bar & $\begin{array}{c}\text { CHO } \\
\text { (cyclohexene oxide) }\end{array}$ & $1 /-/ 100$ & - \\
\hline 5 & $90 \pm 5^{\circ} \mathrm{C} 60 \pm 5$ bar & $\mathrm{SO}$ & $-/ 1 / 100$ & 14 \\
\hline 6 & $90 \pm 5^{\circ} \mathrm{C} 90 \pm 5$ bar & $\mathrm{PO}$ & $-/ 1 / 100$ & $<1$ \\
\hline 7 & $90 \pm 5^{\circ} \mathrm{C} 90 \pm 5$ bar & $\mathrm{BO}$ & $-/ 1 / 100$ & $<1$ \\
\hline 8 & $90 \pm 5^{\circ} \mathrm{C} 80 \pm 5$ bar & $\mathrm{CHO}$ & $-/ 1 / 100$ & - \\
\hline 9 & $90 \pm 5^{\circ} \mathrm{C} 60 \pm 5$ bar & $\mathrm{SO}$ & $1 / 2 / 100$ & 28 \\
\hline 10 & $90 \pm 5^{\circ} \mathrm{C} 90 \pm 5$ bar & $\mathrm{PO}$ & $1 / 2 / 100$ & 40 \\
\hline 11 & $90 \pm 5^{\circ} \mathrm{C} 90 \pm 5$ bar & $\mathrm{BO}$ & $1 / 2 / 100$ & 22 \\
\hline 12 & $90 \pm 5^{\circ} \mathrm{C} 80 \pm 5$ bar & $\mathrm{CHO}$ & $1 / 2 / 100$ & - \\
\hline 13 & $90 \pm 5^{\circ} \mathrm{C} 60 \pm 5$ bar & $\mathrm{SO}$ & $1 / 2 / 1000$ & $<1$ \\
\hline 14 & $90 \pm 5^{\circ} \mathrm{C} 90 \pm 5$ bar & $\mathrm{PO}$ & $1 / 2 / 1000$ & $<1$ \\
\hline 15 & $90 \pm 5^{\circ} \mathrm{C} 90 \pm 5$ bar & $\mathrm{PO}$ & $1 / 20 / 1000$ & 26 \\
\hline 16 & $90 \pm 5^{\circ} \mathrm{C} 90 \pm 5$ bar & $\mathrm{BO}$ & $1 / 2 / 1000$ & $<1$ \\
\hline 17 & $90 \pm 5^{\circ} \mathrm{C} 80 \pm 5$ bar & $\mathrm{CHO}$ & $1 / 2 / 1000$ & - \\
\hline 18 & $90^{\circ} \mathrm{C} 1$ bar & $\mathrm{SO}$ & $1 / 2 / 100$ & 5 \\
\hline 19 & $90^{\circ} \mathrm{C} 1$ bar & $\mathrm{PO}$ & $1 / 2 / 100$ & $<1$ \\
\hline 20 & $90^{\circ} \mathrm{C} 1$ bar & $\mathrm{BO}$ & $1 / 2 / 100$ & $<1$ \\
\hline 21 & $90^{\circ} \mathrm{C} 1$ bar & $\mathrm{CHO}$ & $1 / 2 / 100$ & - \\
\hline $22 \mathrm{ZnCl}_{2}(\mathrm{NMi})_{2}$ & $90 \pm 5^{\circ} \mathrm{C} 40 \pm 5$ bar $^{\mathrm{c}}$ & $\mathrm{PO}$ & $1 / 2 / 100$ & 94 \\
\hline $23 \mathrm{ZnCl}_{2}(\mathrm{NMi})_{2}$ & $90 \pm 5^{\circ} \mathrm{C} 20 \pm 5$ bar $^{\mathrm{c}}$ & SO & $1 / 2 / 100$ & 87 \\
\hline
\end{tabular}

\section{General procedure}

The catalysts were suspended in the epoxide $(20 \mathrm{ml})$ in the presence of 1-methyl-imidazole. The reaction mixture was put under a $\mathrm{CO}_{2}$-atmosphere ( $\mathrm{ca} 25 \mathrm{~g} \mathrm{CO}_{2}$ ) and then heated up to $90^{\circ} \mathrm{C}$ for ca. 10 hours. a) $\mathrm{CO}_{2}$ Pressure and temperature read after 4 hours reaction time. b) the cyclic carbonate yield was evaluated with ${ }^{1} \mathrm{H}-\mathrm{NMR}$ : yield $\%=\operatorname{int}\left(\mathrm{H}_{\text {methine }}\right.$ carbonate $) /\left[\operatorname{int}\left(\mathrm{H}_{\text {methine }}\right.\right.$ 
carbonate $)+\operatorname{int}\left(\mathrm{H}_{\text {methine }}\right.$ epoxide $\left.)\right]$ c) Entry 22: 21 bar $\mathrm{CO}_{2}$ at the beginning $\left(11 \mathrm{~g} \mathrm{CO}_{2}\right)$; Entry 23: 11 bar at the beginning $\left(6 \mathrm{~g} \mathrm{CO}_{2}\right)$.

In order to gather some spectroscopic information on the catalytic system, we ran a couple catalytic tests in high pressure NMR tubes with zinc picolinate, propylene oxide as test substrate and an excess of the co-catalyst to accelerate the solubilisation of the catalyst (molar ratio ca. 1 to 8 instead of 1 to 2 ). The tests were run in a $5 \mathrm{~mm}$ sapphire NMR-tube ${ }^{18}$ under ca. 50 bar $\mathrm{CO}_{2}$, the tube being heated in a silicon-oil bath and regularly shaken. Figure 1 shows the ${ }^{1} \mathrm{H}$ and ${ }^{13} \mathrm{C}$ spectra of the reaction mixture under argon, prior to the pressurization whereas figure 2 shows the NMR-spectra after 10 hours at $90{ }^{\circ} \mathrm{C}$ and ca. 50 bar $\mathrm{CO}_{2}$. Interestingly we could notice the formation of small droplets on the inner wall of the tube which lead eventually to the formation of a second phase at the bottom of the NMR-tube (figure 2). Comparing the ${ }^{13} \mathrm{C}$ spectra of the reaction mixture before and after the reaction, it can be seen that, in the upper phase, the concentration of zinc picolinate (signals at 167.0, 152.0, 147.1, 140.1, 138.4, 129.1, 124.5 and $120.6 \mathrm{ppm}$ ) decreased whereas the concentration of propylene carbonate increased (155.7, 74.2, 71.4 and $19.2 \mathrm{ppm})$. In addition, new ${ }^{13} \mathrm{C}$-signals (68.8, 65.8 and $20.1 \mathrm{ppm}$ ) appeared in regions close to the ${ }^{13} \mathrm{C}$-NMR signals of propylene carbonate as well as in regions close to the signals of 1-methyl-imidazole (150.5, 137.4, $127.1 \mathrm{ppm}$ and $30.4 \mathrm{ppm})$. These new signals can be tentatively attributed to a stable "alkoxy-imidazolium" specie formed from the reaction of the epoxide with imidazole (vide infra for mechanism proposal). After careful depressurisation of the HP NMR-tube, the second phase was investigated with IR and NMR (the isolated oil, hardly soluble in apolar solvents, formed a kind of stable "emulsion" in THF). It can be taken from the first spectroscopic data that the oil displays a composition similar to the upper phase with only traces of propylene carbonate. More work is currently in progress to characterize via the use of 2D-NMR methods (HMQC, HMBC) and ${ }^{13} \mathrm{C}$-labelled $\mathrm{CO}_{2}$ the exact nature of the species present in the two phases. 


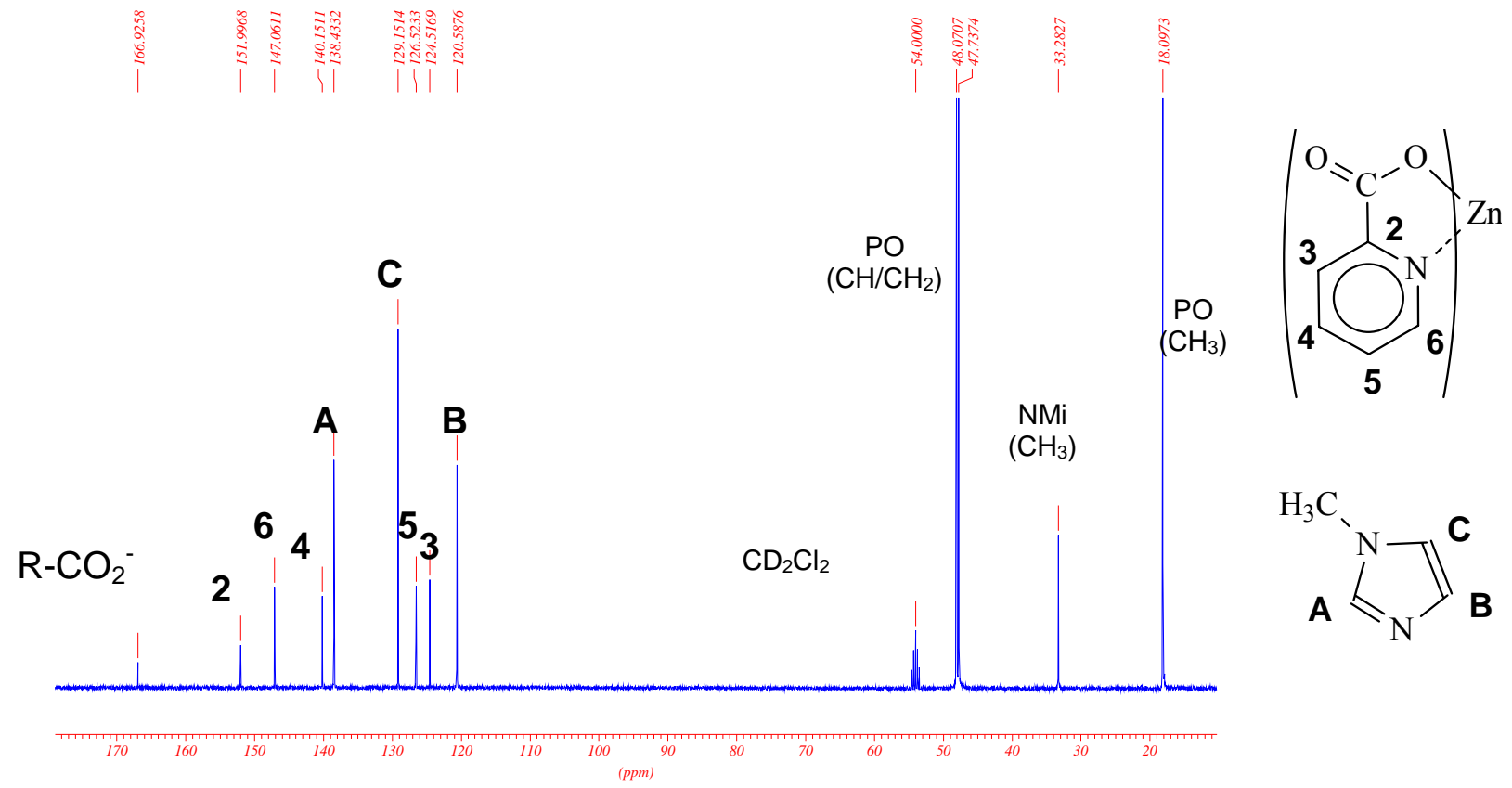

Figure 1. ${ }^{13} \mathrm{C}$-NMR spectrum (in $\mathrm{CD}_{2} \mathrm{Cl}_{2}$ ) of the reaction mixture (zinc picolinate / $\mathrm{NMi} / \mathrm{PO}$ ) under argon before the reaction.

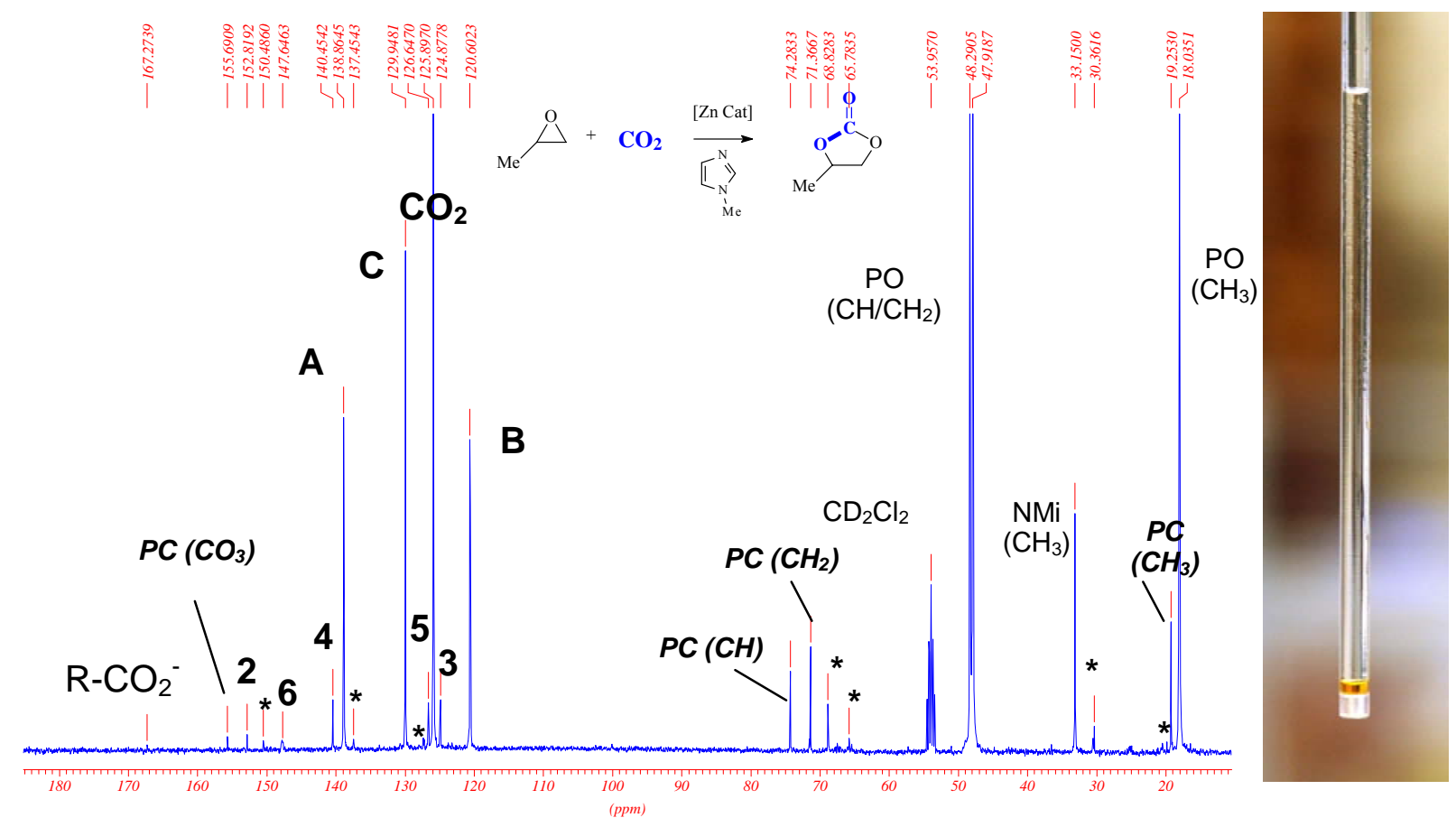

Figure 2. ${ }^{13} \mathrm{C}-\mathrm{NMR}$ spectrum (in $\mathrm{CD}_{2} \mathrm{Cl}_{2}$ ) of the reaction mixture under 50 bar $\mathrm{CO}_{2}$ after reaction (* new signals). 
These observations together with the screening tests allow us to propose a tentative mechanism for the catalytic formation of the cyclic carbonate (scheme 3 ).

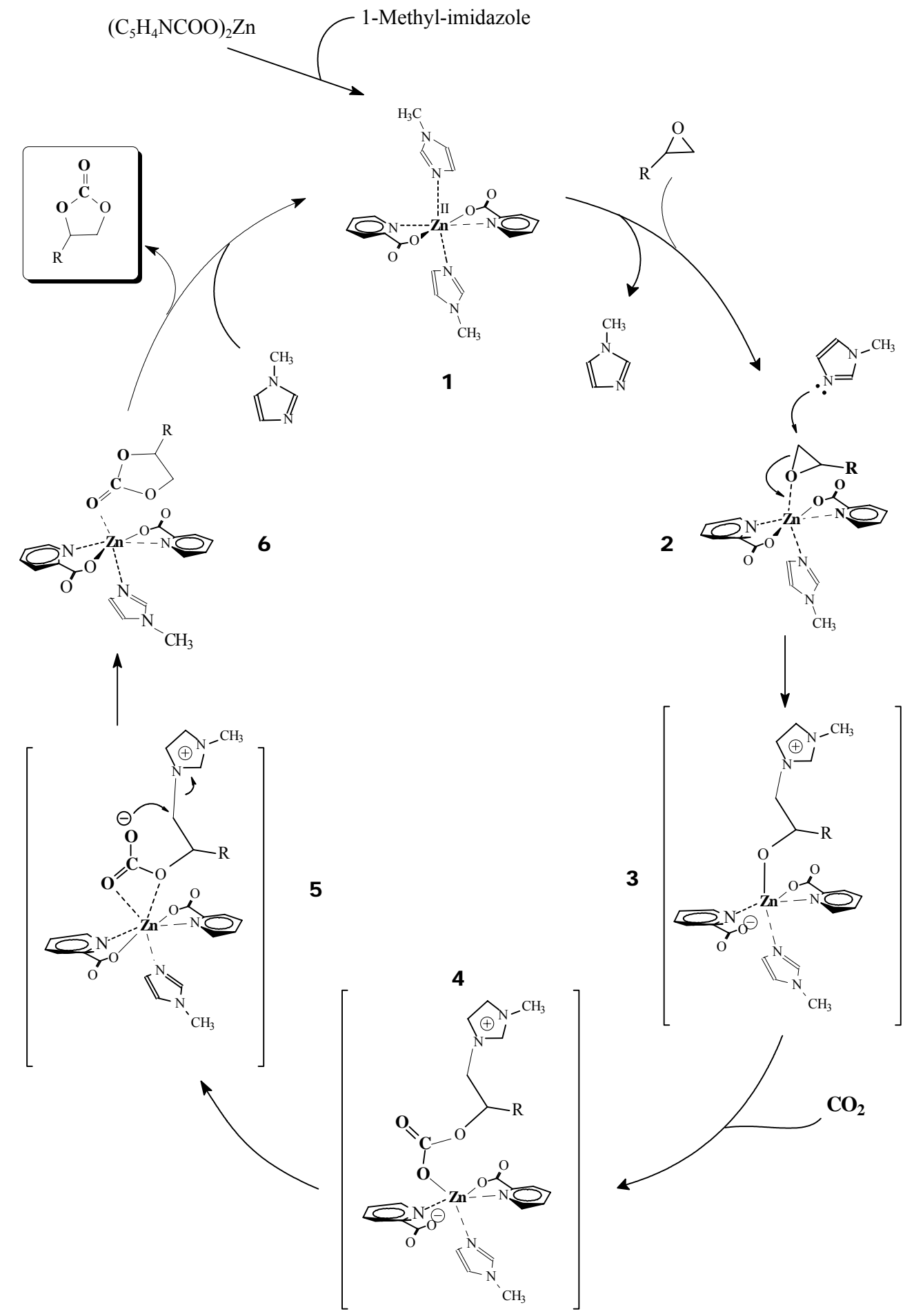

Scheme 3. Mechanism proposal for the zinc picolinate/NMi-catalyzed synthesis of cyclic carbonates. 
The first step of the catalysis involves the formation of a soluble octahedrally coordinated specie [Zn(pyridine-2-carboxylate $\left.)_{2}(1 \text {-methylimidazole })_{2}\right]$ (1). Related compounds based on 2quinoline-carboxylic acid have been reported earlier in the literature ${ }^{19}$. The second step is comparable to the mechanism proposed by Kim in the case of the zinc bromide/pyridinecatalysed synthesis of cyclic carbonates ${ }^{11 \mathrm{j}}$, an initial coordination of the epoxide replacing one of the 1-methyl-imidazole being likely to occur first (2). The zinc(II) center, as Lewis acid catalyst, should promote the formation of such an intermediate. Some related epoxide-Lewis acid adducts were structurally characterized by Darensbourg et al. in the case of cadmium(II) pyrazolylcarboxylato derivatives ${ }^{20}$. A nucleophilic attack of the free 1-methyl-imidazole on the less sterically hindered carbon atom of the coordinated epoxide generate a reactive "alkoxyimidazolium" specie (intermediate 3). Such intermediates involving epoxide and imidazole were already reported for the imidazole-catalyzed curing of epoxy resins ${ }^{17}$. It is likely that the formation of a second phase observed in some of the test reactions (a.o. in HP-NMR tube with PO) is due to the formation of stable a "alkoxy-imidazolium" zinc carboxylato compound. This zinc-alkoxo specie would react in the third step of the catalytic cycle with carbon dioxide to form, via an insertion into the $\mathrm{Zn}-\mathrm{O}$ bond, a "carbonato-imidazolium" intermediate (intermediate 4) ${ }^{11 \mathrm{~b}, 11 \mathrm{~h}}$. In opposition to the system described by Kim and co-workers ${ }^{11 \mathrm{~h}}$, zinc picolinate in not likely to form dinuclear species displaying a bridged "carbonato-imidazolium" which can easily undergo a cyclization to form the cyclic carbonate. In our case, the rearrangement of the "carbonato-imidazolium" intermediate is likely to happen in an intramolecular way (intermediate 5). However, the possibility that an ancillary zinc picolinate(NMi) $)_{2}$ monomer might play a role in the cyclization of the "carbonato-imidazolium" specie cannot be completely ruled out. In the last step of the cycle, the Levis acidity of the zinc carboxylate is not high enough to form a stable zinc picolinate-cyclic carbonate adduct ${ }^{21}$, the cyclic carbonate is then released and the zinc center is free for a new coordination of the epoxide.

\section{Summary and Conclusions}

Despite displaying a lower catalytic activity in the formation of cyclic carbonates than the $\mathrm{ZnCl}_{2}$ based catalytic systems, this cheap and easy-to-handle zinc carboxylate is a promising starting point for new ways to synthesize cyclic carbonates. More work is currently in progress to optimize this binary system (a.o. broadening the substrate range, tuning the co-catalyst, dealing with the formation of a second phase), to better understand the various reaction steps as well as unequivocally characterize some of the intermediates involved in the catalysis. 


\section{Experimental Section}

General Procedures. Styrene oxide, butene oxide, propylene oxide and cyclohexene oxide (Aldrich) were distilled under vacuum over $\mathrm{CaH}_{2}$. 1-methyl-imidazole (Aldrich, GC grade) was stored immediately after purchase over molecular sieves and used without further purification. Carbon dioxide (Messer Griesheim, purity 99.9990\%) was used without further purification. NMR deuteriated solvents (Chemotrade) were degassed, dried over molecular sieves Linde $4 \AA$ and stored under argon. The NMR spectra of reaction mixtures, final products $\left(\mathrm{C}_{6} \mathrm{D}_{6}\right.$ or $\mathrm{CDCl}_{3}$ solutions) and HP-NMR experiments $\left(\mathrm{CD}_{2} \mathrm{Cl}_{2}\right)$, were recorded with a Varian Inova 400 spectrometer $\left({ }^{1} \mathrm{H} 399,81 \mathrm{MHz},{ }^{13} \mathrm{C}: 100.54 \mathrm{MHz}\right)$. TMS was used as internal standard $\left({ }^{13} \mathrm{C},{ }^{1} \mathrm{H}\right)$ with different deuteriated solvents. The chemical shifts $\delta$ (in ppm) are given relative to the residual signal of the solvent. Infrared spectra (thin films between $\mathrm{KBr}$ plates or KBR pellets) were recorded on a BIORAD 175C FT-IR spectrometer in the range of 4000-400 $\mathrm{cm}^{-1}$.

\section{Synthesis of the catalyst}

Zinc(II) pyridin-2-carboxylate (zinc picolinate) was prepared according to the "oxide way" 16a, 22 : 0.1 mole of the corresponding acid were dissolved in 50 to $200 \mathrm{ml}$ of deionized water. 0.05 mole of zinc oxide were added to this solution, the suspension was then heated at $90{ }^{\circ} \mathrm{C}$ for 2 hours. The resulting solution was filtered and concentrated. Over a period of one day colorless crystals formed (yields ranging from $95 \%$ to $98 \%$ ). Zinc picolinate was filtered, dried a first time at $120^{\circ} \mathrm{C}$, grinded, dried again for 24 hours at $120^{\circ} \mathrm{C}$ and eventually stored under argon.

\section{General procedure for autoclave experiments and HP-NMR}

The catalytic screening tests were performed in a "multi-reactor" system involving 4 high pressure reactors equipped with magnetically coupled stirring systems and electrical heating mantles ${ }^{23}$. Temperature and pressure were monitored via a digital multimeter (HP 34970A) connected to a personal computer. The catalytic tests were typically conducted in $70 \mathrm{~mL}$ stainless steel (SS316) autoclaves equipped with standard Swagelock fittings. The reactors were heated overnight at $100{ }^{\circ} \mathrm{C}$ and purged with argon prior to use. The epoxide $(20 \mathrm{ml})$ were transferred into the autoclave, the catalyst (catalyst/epoxide molar ratio: 1 to 100 or 1 to 1000) and NMi (catalyst/co-catalyst molar ratio: 1 to 2 ) were added to the epoxide. The reactor was then pressurized with $\mathrm{CO}_{2}$ (60 bar) for a few minutes under stirring and afterwards weighted, the procedure was repeated until carbon dioxide was clearly in excess $\left(\mathrm{CO}_{2} /\right.$ epoxide molar ratio ranging from 1,6 for PO to 3 for $\mathrm{CHO}$, around $25 \mathrm{~g} \mathrm{CO}_{2}$ ). The reactors were heated overnight at $90{ }^{\circ} \mathrm{C}$. After the reaction time the autoclaves were cooled down to RT (water bath) and the carbon dioxide slowly vented, under stirring, in a fume hood. After opening the remaining solution was filtered and analyzed with NMR and IR-FT.

High-pressure NMR experiments were run in a $5 \mathrm{~mm}$ HP NMR sapphire tube fitted with

titanium-based alloy valves $(90 \% \mathrm{Ti}, 6 \% \mathrm{Al}, 4 \% \mathrm{~V}){ }^{18}$. The tube was filled with the different components under argon and then connected to a "pressurizing station" (Vaccum/Argon $/ \mathrm{CO}_{2}$ 
lines) via Swagelock fittings. The tube was then sealed and heated in a silicon oil bath for 8 hours at $90^{\circ} \mathrm{C}$. During this period of time the tube was occasionally taken from the heating bath, cleaned and shaken on a test tube vortex mixer.

\section{Spectroscopic characterization of the synthesized cyclic carbonates}

Propylene carbonate (2-methyl-1,2-ethylene carbonate), $\mathbf{C}_{4} \mathbf{H}_{\mathbf{6}} \mathbf{O}_{3}$, [108-32-7]. IR (nujol, $\mathrm{cm}^{-}$ 3): 2990 (s), 2930 (s), $1793(\mathrm{vs}), 1485$ (w), 1557 (w), 1388 (m), 1354 (m), 1184 (s), 1120 (m), 1053(s), $777(\mathrm{~m}), 712(\mathrm{~m}) ;{ }^{1} \mathrm{H}$ NMR $\left(\mathrm{CDCl}_{3}\right): \delta(\mathrm{ppm})=4.78\left(\mathrm{~m}, \mathrm{R}-\mathrm{CH}-\mathrm{CH}_{2}\right), 4.47(\mathrm{dd}, 7.22 \mathrm{~Hz}$ 8.39Hz R-CH-CHH), 3.92 (dd, 7.71Hz 8.50Hz R-CH-CHH); 1.37 (d, $\left.6.0 \mathrm{~Hz}, \mathrm{CH}_{3}-\mathrm{CH}-\mathrm{CH}_{2}\right) ;{ }^{13} \mathrm{C}$ NMR: $\left.\delta(\mathrm{ppm})=154.78\left(\mathrm{R}-\mathrm{CO}_{3}-\right) ; 73.01\left(\mathrm{R}-\mathrm{CH}-\mathrm{CH}_{2}\right), 70.07 \mathrm{R}-\mathrm{CH}-\mathrm{CH}_{2}\right) ; 18.95\left(\mathrm{CH}_{3}-\mathrm{CH}-\right.$ $\left.\mathrm{CH}_{2}\right)$.

Butene carbonate (1,2-butylene carbonate), $\mathbf{C}_{5} \mathbf{H}_{8} \mathbf{O}_{3}$, [4437-85-8]. IR (nujol, $\mathrm{cm}^{-3}$ ): 2967 (s), 2936 (s), 2879 (s), 1795 (s), 1457(s), 1062 (s); ${ }^{1} \mathrm{H}$ NMR $\left(\mathrm{CDCl}_{3}\right): \delta$ (ppm): 4.57 (m, R-CH-CH$)$, 4.42 (dd t, 7.47Hz, R-CH-CHH), 3.97 (dd t, 8.35Hz, R-CH-CHH); 1.64 (m, CH3-CH2-CH$\mathrm{CH}_{2}$ ); 0.90 ( $\sim$, $\left.6.6 \mathrm{~Hz}, \mathrm{CH}_{3}-\mathrm{CH}_{2}-\mathrm{CH}-\mathrm{CH}_{2}\right)$; ${ }^{13} \mathrm{C} \mathrm{NMR:} \delta(\mathrm{ppm})$ : $154.88\left(\mathrm{R}-\mathrm{CO}_{3}-\right)$; $77.95(\mathrm{R}-\mathrm{CH}-$ $\left.\mathrm{CH}_{2}\right), 68.99$ R-CH-CH 2$) ; 26.62\left(\mathrm{CH}_{3}-\mathrm{CH}_{2}-\mathrm{CH}-\mathrm{CH}_{2}\right) ; 8.21\left(\mathrm{CH}_{3}-\mathrm{CH}_{2}-\mathrm{CH}-\mathrm{CH}_{2}\right)$.

Styrene carbonate (2-phenyl-1,2-ethylene carbonate), $\mathrm{C}_{9} \mathrm{H}_{8} \mathrm{O}_{3}$, [4427-92-3]. White crystalline solid (needles, fusion point $52-53^{\circ} \mathrm{C}$ ) isolated via flash chromatography. IR (nujol, $\mathrm{cm}^{-3}$ ): 3067 (m), 2980 (w), 2925 (w), 1778 (vs), 1497(m), 1477(m), 1458(m), 1358, 1392(m), 1328, 1170 (s), 1055 (s), 759 (s), 699 (s); ${ }^{1} \mathrm{H}$ NMR $\left(\mathrm{CDCl}_{3}\right): \delta(\mathrm{ppm}): 5.62\left(\mathrm{t}, \mathrm{R}-\mathrm{CH}-\mathrm{CH}_{2}\right), 4.75(\mathrm{t}, 7.22 \mathrm{~Hz} \mathrm{R}-$ $\mathrm{CH}-\mathrm{CHH}), 4.27$ (t, 7.71Hz R-CH-CHH); 7.4-7.3(m, $\left.\mathrm{C}_{6} \mathrm{H}_{5}-\mathrm{CH}-\mathrm{CH}_{2}\right) ;{ }^{13} \mathrm{C}$ NMR: $\delta(\mathrm{ppm}): 154.78$ $\left(\mathrm{R}-\mathrm{CO}_{3}{ }^{-}\right) ; 135.65(\mathrm{C} 1), 129.53(\mathrm{C} 4), 129.03$ (C3,C5), 125.77 (C2,C6), $77.85\left(\mathrm{R}-\mathrm{CH}-\mathrm{CH}_{2}\right), 71.02$ $\left(\mathrm{R}-\mathrm{CH}-\mathrm{CH}_{2}\right)$.

\section{Acknowledgements}

The authors are thankful for financial support from the program "Sustainability and Technology" of the Helmholtz Association of National Research Centres. The authors would like to thank Diana Deutsch for technical support.

\section{References}

1. (a) Behr, A. Carbon dioxide activation by metal complexes, VCH: Weinheim, 1988. (b) Marks, T. J. et al. Chem. Rev. 2001, 101, 953. (c) Dinjus, E.; Fornika, R.; Pitter, S.; Zevaco, T. A. "Carbon Dioxide as a $\mathrm{C}_{1}$ Building Block", In Applied Homogeneous Catalysis with Organometallic Compounds, B. Cornils / W.A. Herrmann, Ed.; 1189-1208, Wiley-VCH: Weinheim, 2002; pp 1189 - 1208. (d) Omae, I. Catalysis Today 2006, 115, 33. 
2. For comprehensive reviews see (a) Sugimoto, R.; Inoue, S. J. Polym. Sci.: Part A: Polym. Chem. 2004, 42, 5561. (b) Darensbourg, D. J.; Mackiewicz, R. M.; Phelps, A. L.; Bilodeaux, D. R. Acc. Chem. Res. 2004, 37, 836. (c) Coates, G. W.; Moore, D. R. Angew. Chem. Int. Ed. 2004, 43, 6618.

3. (a) Storzer, U.; Walter, O.; Zevaco, T.A.; Dinjus, E. Organometallics 2005, 24, 514. (b) Buchmuller, K.; Dahmen, K.; Dinjus, E.Neumann, D.; Powietzka, B.; Pitter, S.; Schon, J. Green Chemistry 2003, 5, 218. (c) Behr, A.; Brehme, V. A. J. Mol. Cat. A-Chemical 2002, $187,69$.

4. (a) Kishimoto, Y.; Mitani, I. Synlett 2005, 14, 2141. (b) Tekavec, T. N.; Arif, A. M.; Louie, J. Tetrahedron 2004, 60, 7431. (c) D. Walther, D.; Dinjus, E.; Schönberg, H.; Sieler, J. J. Organomet. Chem. 1987, 334, 377.

5. (a) Jansen, A.; Pitter, S. J. Mol. Cat. A: Chemical 2004, 217, 41. (b) P. Deglmann, P. E. Ember, E.; Hofmann, P.; Pitter, S.; Walter, O. Chem. Eu. J. 2006 in press.

6. For comprehensive reviews see (a) Clements, J. H. Ind. Eng. Chem. Res. 2003, 42, 663. (b) Shaikh, A.; Sivaram, S. Chem. Rev. 1996, 96, 951.

7. (a) Machac, J.; Marquis, T. U.S. Patent 6187 108, 2001. (b) Nodelman, N. U.S. Patent 5 149 458, 1992. (c) Klein, H.; Marquis, T. Coat. World 1997, 2, 3, 38.

8. Wakihara, M.; Yamamoto, O. Lithium Ion Batteries - Fundamentals and Performance; Wiley-VCH: Weinheim, 1998.

9. (a) Fukuoka, S.; Kawamura, M.; Komiya, K.; Tojo, M.; Hachiya, H.; Hasegawa, K.; Aminaka, M.; Okamoto, H.; Fukawa, I.; Konno, S. Green Chemistry 2003, 5, 497. (b) H. Nava, U.S. Patent 5969 056, 1999. (c) Lazarus, S.; Lofquist, R. U.S. Patent 4348 314, 1982.

10. (a) Anderson, A. U.S. Patent 5977 262, 1999. (b) Angeles, E.; Santillan, A.; Martinez, I. Ramirez, A.; Moreno, E. Synth. Commun. 1994, 24, 2441.

11. (a) Dümler, W.; Kisch, H. Chem. Ber. 1990, 123, 277. (b) Kihara, N.; Hara, N.; Endo, T. J. Org. Chem., 1993, 58, 6198. (c) Kasuga, K.; Kabata, N. Inorg. Chim. Acta. 1997, 257, 277. (d) Kasuga, K.; Nagao, S.; Fukumoto, T.; Handa, M. Polyhedron 1996, 15, 69. (e) Sako, T.; Fukai, T.; Sahashi, R.; Sone, M.; Matsuno, M. Ind. Eng. Chem. Res. 2002, 41, 5353. (f) Lai, G. Q.; Peng, J. J.; Li, J. Y.; Qiu, H. Y.; Jiang, J. X.; Jiang, K. Z.; Shen, Y. J. Tetrahedron Lett. 2006, 47, 6951. (g) Palgunadi, J.; Kwon, O. S.; Lee, H.; Bae, J. Y.; Ahn, B. S.; Min, N. Y.; Kim, H. S. Catal. Today 2004, 98, 511. (h) Kim, H. S.; Kim, J. J.; Lee, S. D.; Lah, M. S.; Moon, D.; Jang, H. G. Chem. Eur. J. 2003, 9, 678.

12. (a) Paddock, R. L.; Nguyen, S. T. J. Am. Chem. Soc. 2001, 123, 11498. (b) Kruper, W. J.; Dellar, D. V. J. Org.Chem. 1995, 60, 725. (c) Tascedda, P.; Weidmann, M.; Dinjus, E.: Dunach, E, Appl. Organometal. Chem. 2001, 15, 141. (d) Lu, X. B.; Ren, H. W. J. Mol. Cat. A: Chemical 2002, 186, 33. (e) Bringmann, J.; Dinjus, E. Appl. Organomet. Chem. 2001, 15, 135.

13. (a) Yamaguchi, K.; Ebitani, K.; Yoshida, T.; Yoshida, H.; Kaneda, K. J. Am. Chem. Soc. 1999, 121, 4526. (b) Yano, T.; Matsui, H.; Koike, T.; Ishiguro, H.; Fujihara, H.; Yoshihara, 
M.; Maeshima, T. Chem. Commun. 1997, 1129. (c) Tu, M.; Davis, R. J. Journal of Catalysis 2001, 199, 85. (d) Ramin, M.; Van Vegten, N.; Grunwald, J. D.; Baiker, A. J. Mol. Cat., AChemical 2006, 258, 165.

14. (a) Kimura, E. Tetrahedron 1992, 48, 6175. (b) Kato, M. T. Ito, Inorg. Chem. 1985, 24, 504. (c) Ruf, M.; Vahrenkamp, H. Inorg. Chem. 1996, 35, 6571.

15. (a) Aida, T.; Inoue, S. Acc. Chem. Res. 1996, 29, 39. (b) Kuran, W.; Listos, T. Macromol. Chem. Phys. 1994, 195, 977. (c) Darensbourg, D. J.; Wildeson, J. R.; Yarbrought, J. C. Inorg. Chem. 2002, 41, 973. (d) Darensbourg, D. J.; Zimmer, M. S. Macromolecules 1999, 32, 2137.

16. (a) Motika, S. A.; Pickering, S. L.; Rokicki, A.; Stein, B. K. U.S. Patent 5026 676, 1991. (b) Sun, H.-N. U.S. Patent 4783 445, 1988. (c) Kawaschi, H.; Minami, S.; Armor, J. N.; Rokicki, A.; Stein, B. K. U.S. Patent 4981 948, 1991. (d) Super, M.; Berluche, E.; Costello, C.; Beckmann, E. Macromolecules 1997, 30, 368. (e) Kim, J. S.; Kim, H.; Yoon, J.; Heo, K.; Ree, M. J. Polym. Sci.: Part A: Polym. Chem. 2005, 43, 4079.

17. (a) Ricciardi, F.; Joullie, M. M.; Romanchick, W. A.; Gricavage, A. A. J. Polym. Sci., Polym. Lett.Ed. 1982, 20, 127. (b) Fedtke, M.; Strehmel, V. Acta Polymerica 1989, 40, 497. (c) Jones, J. R.; Poncipe, C.; Barton, J. M.; Wright, W. W. Polymer 1987, 28, 1358.

18. For more information on HP NMR tubes based on the "Titanium- Sapphire" technology see (a) Roe, D. C. J. Magn. Reson. 1985, 63, 388. (b) Horvath, I. T.; Ponce, E. C. Rev. Sci. Instrum. 1991, 62, 1104. (c) Cusanelli, A.; Frey, U.; Richens, D. T.; Merbach, A. E. J. Am. Chem. Soc. 1996, 118, 5265.

19. Zevaco, T. A.; Goerls, H.; Dinjus, E. Inorg. Chim. Acta 1998, 269, 283.

20. Darensbourg, D. J.; Niezgoda, S. A.; Holcamp, M. W.; Draper, J. D.; Reibenspies, J. H. Inorg. Chem. 1997, 36, 2426.

21. For the structural characterization of a Zinc(II) phenoxide-propylene carbonate adduct see Darensbourg, D. J.; Holtcamp, M. W.; Struck, G. E.; Zimmer, M. S.; Niezgoda, S. A.; Rainey, P.; Robertson, J. B.; Draper, J. D.; Reibenspies, J. H. J. Am. Chem. Soc. 1999, 121, 107.

22. Lumme, P.; Lundgren, G.; Mark, W. Acta Chemica Scandinavica 1969, 23, 3011.

23. (a) Zevaco, T. A.; Janssen, A.; Sypien, J.; Dinjus, E. Green Chemistry 2005, 7, 659. (b) Zevaco, T. A.; Sypien, J.; Janssen, A.; Walter, O.; Dinjus, E. Catalysis Today 2006, 115, 151. 